\title{
Heat Shock Proteins in Inflammation
}

\author{
Z. Bromberg, Y.G. Weiss, and C.S. Deutschman
}

\section{Introduction}

From roundworms to mammals, living organisms have evolved strategies to permit survival in divergent environments. Evidence shows that some of these adaptive biological features are evolutionarily conserved; among these is heat acclimation. This phenomenon was described first as inducing physiological and biochemical adaptations to protect against extreme changes in environmental temperature [1]. This "heat shock response" is now accepted widely as a key mechanism to protect cells from untoward environmental perturbations [2].

The heat shock response was first identified in Drosophila melanogaster [3]. Early experiments showed that exposure to heat led to "chromosomal puffing" that correlated with a dramatic increase in the synthesis of a previously unrecognized group of proteins [3]. This finding was later extended to other eukaryotic organisms. These 'heat shock proteins' (HSPs) appeared to mediate a molecular mechanism that protected living cells from the untoward effects of heat [3]. Of these, one of the most widely studied is the $70 \mathrm{kDa}$ HSP (HSP70). The genes encoding members of the HSP70 family are a key evolutionary adaptation that is conserved across species. The HSP70 gene is genetically simple, with a single exon and no introns, which permits rapid transcription and translation $[4,5]$. Of the $70 \mathrm{kDa}$ subfamily members, the inducible HSP72 is highly expressed during stress while the constitutive heat shock cognate protein (HSC)70 (also known as HSP73) is constitutively expressed, with basal levels present in the cytosol at most times [6].

Within the cytosol of eukaryotic cells, members of the 70 to $78 \mathrm{kDa}$ subfamily of HSPs bind to and release both non-native protein aggregates and native proteins with incomplete or damaged tertiary structures [6]. In this sense, HSP70 family members act as molecular chaperones to 'guide' proteins to their ultimate fate-degradation, elimination, repair, or completion of the synthetic process. The chaperone's 'guiding' mechanism relies on recognition of hydrophobic regions of non-native proteins or unstructured back-bone regions of proteins. They promote the correct protein folding through cycles of substrate binding and release. This is regulated through a catalytic site by an energy-requiring ATPase dependent mechanism $[3,5,7,8]$.

Under environmental stress conditions, misfolded protein intermediates may accumulate. [9]. The self-association of non-native protein intermediates to nearby 
proteins may induce the formation of protein aggregates [10]. In contrast to misfolding, aggregation is a highly cooperative inter-molecular process that strongly depends on the concentration of misfolded monomers. Aggregates may be composed of different oligomers over a wide distribution of sizes. The presence of these aggregates is common in a number of disease processes, including neurodegenerative disorders such as Alzheimer's, Parkinson's, and Huntington's diseases. The exposure of hydrophobic protein domains to unaffected proteins or membranes may disrupt normal activity. For example, association of the hydrophobic region of a damaged protein with a neuronal cell membrane may change ion flux and alter function. HSP70 may prevent this and this may be a key mechanism by which HSPs limit or prevent intra-cellular pathological processes. This underscores the fundamental importance of the HSPs to normal living cells [11].

While this review will focus on HSP70, other subclasses among the HSPs play important roles. These are organized by their molecular size: HSP100, HSP90, HSP60, HSP40 (J-domain proteins) and small HSP families, such as HSP22/27 [12,13]. Most HSPs are constitutively and ubiquitously expressed molecular chaperones that guide the normal folding, intracellular disposition, and proteolytic turnover of many of the key regulators of cell growth and survival [14]. Thus, the protective process involves the interaction of many different HSPs. For example, HSP90, which comprises 1-2\% of total cellular protein in non-stress conditions [15], supports meta-stable protein conformations and expresses a high affinity binding state to hormone receptors. This involves both HSP70, which participates in assembly of multiprotein complexes, and HSP40, a co-chaperone that stimulates HSP70 ATPase activity [14].

At the transcription level, HSPs, such as HSP70 and HSP90, are regulated by the activities of a family of heat shock transcription factors (HSF). One of these, HSF-1, normally is expressed in a negatively regulated state as an inert monomer in either the cytoplasm or nuclear compartments [16]. Upon exposure to a variety of stresses, HSF-1 trimerizes and accumulates in the nucleus. HSF-1 trimers bind DNA regions called heat shock elements (HSEs) with high affinity. Some small HSPs are transcribed constitutively due to multiple binding of low levels of HSF1 [16].

The great divergence in HSP70 expression explains the multiple function of these proteins. Elevated levels of HSP70 following diverse inciting causes have led researchers to conclude that HSP70 is involved in cellular protection in the normothermic environment $[4,17,18]$. A wide range of noxious stimuli, such as hypoxia, ischemia/reperfusion, hypoglycemia, endotoxemia, inflammation, and exposure to heavy toxic metals or reactive oxygen species (ROS), induce HSP70 expression in a large number of tissues. Since HSPs respond to environmental changes, expression in organs that are 'outside' the organism (for example, skin, lung, gastrointestinal epithelium) may occur in the absence of any apparent insult [17-24].

It has been demonstrated, both in vivo and in vitro, that exposure to a mild stress, such as heat pretreatment, induces high levels of HSP70. Increased HSP70 levels may confer protection from subsequent noxious stimuli and result in 'cyto- 
protection'. This should be of benefit against cellular injury caused by inflammation and infection [17-23]. Thus, altering HSP70 expression might be of importance in modulating highly lethal inflammatory diseases.

\section{Heat Shock Proteins as 'Disease Regulators': Sepsis and Acute Respiratory Distress Syndrome (Fig. 1)}

Sepsis, as well as the related systemic inflammatory response syndrome (SIRS), and multiple organ dysfunction syndrome (MODS), are the leading causes of death in patients in surgical intensive care units (ICUs) $[24,25]$. The lung is the organ most affected in MODS, with pulmonary dysfunction taking the form of the acute respiratory distress syndrome (ARDS), an often lethal inflammatory disorder of the lung [26]. Recent data from the USA indicate that the mortality rate associated with ARDS is greater than $35 \%$ [26].

ARDS is characterized by an increased inflammatory process in the lungs. In this disorder, alveolar epithelial cells are damaged and ultimately may be destroyed $[27,28]$. While some contributory pathophysiologic mechanisms have been identified, most remain obscure. Therefore, a better understanding of the fundamental biological changes leading to ARDS would be of scientific and therapeutic value.

Several papers have explored the role of HSP70 in a model of lipopolysaccharide (LPS)-induced lung injury. These investigators concluded that heat pre-treatment
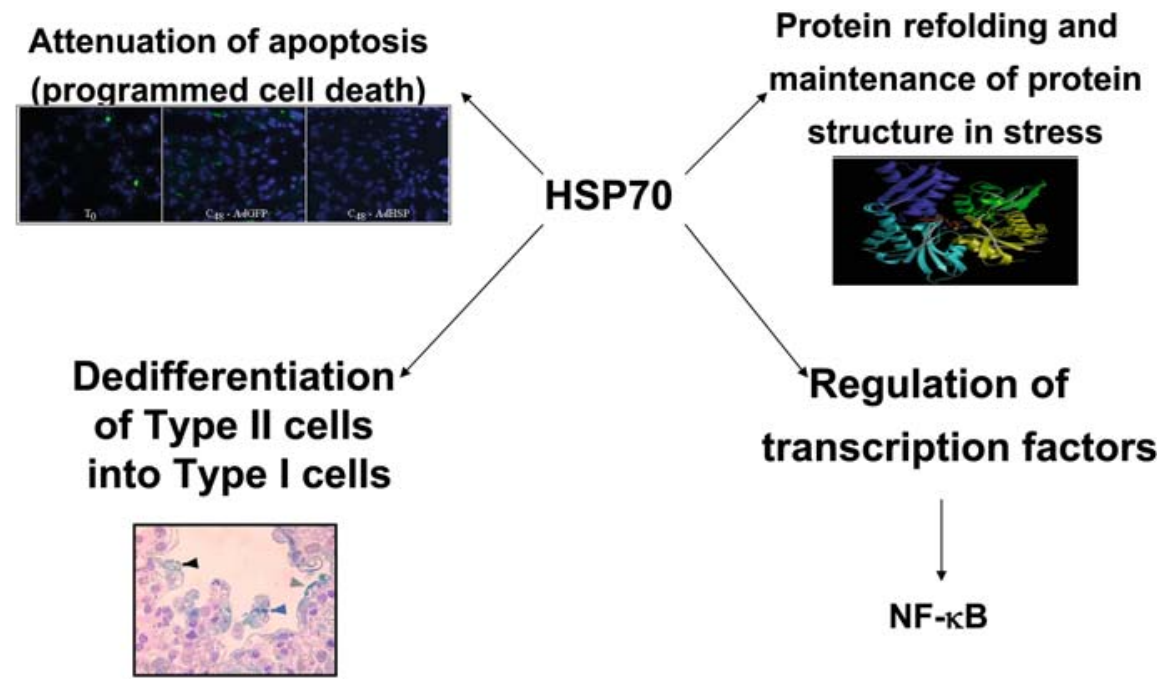

Fig. 1. Cytoprotective functions of heat shock protein (HSP)-70 of potential importance in lung injury and organ failure 
induced HSP70 expression that protected the lungs against ventilator-induced lung injury (VILI) by decreasing cytokine transcription in the lung [29].

LPS stimulates the production and the release of many endogenous mediators of sepsis. These include tumor necrosis factor alpha (TNF- $\alpha$ ), interleukin (IL)-1 and IL-6 [29]. A distinct profile in the expression of genes encoding members of the HSP70 family was demonstrated in leukocytes obtained from different phases of the disease course in septic patients [30]. These findings strongly suggest that HSP70 may play a role in the outcome of septic shock patients [30]. Further, studies proved that in an animal model of ARDS, heat pretreatment prevented mortality [31].

Previous studies had revealed that sepsis induced by cecal ligation and double puncture (CLP) resulted in an ARDS-like state characterized by neutrophil accumulation and protein-rich interstitial edema formation [27, 31, 32-38]. Using this model, we found impaired hepatic expression of several essential liverspecific genes, including those encoding proteins that catalyze gluconeogenesis, $\beta$-oxidation of fatty acids, ureagenesis, and bile acid transport [39-41]. Further, we have demonstrated inappropriate downregulation of the expression of several key genes within the lung. These include surfactant proteins (SP)-A and (SP)-B and, most importantly, HSP70 [27, 42,43]. We found that HSP70 mRNA increased after a sham operation but failed to increase after CLP [27]. HSP70 protein levels were unchanged after either CLP or sham operation. Therefore, HSP70 mRNA fails to increase after CLP despite significant damage to alveolar cells. This lack of increase in HSP70 implies profound pulmonary epithelial dysfunction, similar to our findings in the liver, and is supported by several other studies indicating that sepsis and endotoxemia impair HSP70 expression [23, 27,32,44]. These experiments led us to investigate in depth the role of HSP70 in ARDS and inflammation, by using an adenovirus (AdHSP) to enhance HSP70 expression [38].

We have demonstrated that intratracheal administration of AdHSP significantly attenuates lung injury in rats with sepsis-induced respiratory distress [38]. AdHSP, when compared to phosphate buffer saline (PBS) or a virus expressing a marker protein (AdGFP), attenuated CLP-induced neutrophil accumulation, septal thickening, interstitial fluid accumulation, and alveolar protein exudation [38]. More importantly, AdHSP treatment significantly decreased mortality in rats subjected to CLP [38]. In contrast to studies that provoked the entire heat shock response $[31,45,46]$, our investigations present a unique approach to explore the effects of HSP70 on a single tissue, the lung [32]. We previously documented that AdHSP preferentially increases HSP70 expression in pulmonary epithelial cells [38]. An interesting finding was that 48 hours following CLP, virus uptake occurred primarily in pulmonary epithelial cells, especially type II pneumocytes [32]. 


\section{HSP70 Inhibits Pro-inflammatory Cell Signaling Pathways in ARDS}

The heat shock response is known to modulate inflammation [2]. The mechanisms that have been investigated involve the attenuation of both cytokine-induced inflammatory mediator production and apoptosis [2, 22,31, 45]. Both processes are important in the pathogenesis of ARDS [48-50]. This involves cytokines such as TNF- $\alpha$ and IL- $1 \beta[48-50,54]$.

HSP70 inhibits the apoptotic machinery including the apoptosome, the caspase activation complex, and apoptosis inducing factor [55-57]. HSP70 also participates in the proteasome-mediated degradation of apoptosis-regulatory proteins [58].

TNF- $\alpha$ and IL- $1 \beta$ exert their effects in part via cell signaling pathways involving the nuclear transcription factor, nuclear factor- $\kappa \mathrm{B}(\mathrm{NF}-\kappa \mathrm{B})$ [59-61]. This important acute inflammatory pathway is modulated by HSP70. NF- $\kappa \mathrm{B}$ is a dimeric protein, most often consisting of two subunits, p50 and p65 (Rel A). Normally, this dimer is retained in the cytoplasm by an inhibitory molecule, I $\kappa \alpha \alpha$ [62]. An essential step in NF- $\kappa B$ activation is $I \kappa B \alpha$ degradation. This permits the migration of NF- $\kappa B$ into the nucleus where it can initiate transcription $[61,62]$. Degradation of $\mathrm{I} \kappa \mathrm{B} \alpha$ involves three sequential biochemical reactions. The first is phosphorylation of $\mathrm{I} \kappa \mathrm{B} \alpha$ by I $\mathrm{KB}$ kinase (IKK). IKK is a complex molecule that contains two catalytic subunits, IKK $\alpha$ and IKK $\beta$, an essential regulatory subunit IKK $\gamma g$ also called NF- $\kappa B$ essential modulator (or NEMO) [63], and a recently identified co-modulator, the $105 \mathrm{kDa}$ protein, ELKS [64-66]. The dominant catalytic subunit in inflammation is IKK $\beta$ [61]. Phosphorylation of I $\kappa \mathrm{B} \alpha$ is followed by poly-ubiquitination by $\mathrm{SCF}^{\beta-\operatorname{TrCP}}$ ubiquitin ligase and, finally, proteolysis by the $26 \mathrm{~S}$ proteasome [67-70].

Several in vitro models have proven that heat shock or elevated levels of HSP70 suppresses NF- $\kappa B$ activity and that this inhibition of NF- $\kappa B$ results in a general reduction in the inflammatory response $[44,46,71,73]$. However, the exact molecular mechanism of the HSP70-NF- $\kappa$ B interaction is still unknown. Ran et al. [74] demonstrated that HSP70 promotes rather than inhibits TNF-mediated cell death, by binding to IKK $\gamma$. This resulted in inhibition of IKK activity and consequently inhibited NF- $\kappa$ B-dependent antiapoptotic gene induction [74]. Earlier, Yoo et al. demonstrated that HSP70 prevented phosphorylation of IкB $\alpha$ by IKK $\beta$ [71].

Both activation and modulation of inflammation require coupling of extracellular signals with intra-cellular events, processes involving a number of specific biochemical pathways. We investigated the hypothesis that AdHSP limits sepsisinduced acute inflammation within alveolar epithelial cells in part by suppressing $\mathrm{NF}-\kappa \mathrm{B}$ activation. In contrast to the observations of others $[71,74]$, we found that HSP70 reduced, but did not abolish, IKK $\beta$ activity. More importantly, we have uncovered a novel mechanism of $\mathrm{I} \kappa \mathrm{B} \alpha$ stabilization that results from an association with HSP70 [75]. HSP70 binds to an incomplete protein degradative complex composed of phosphorylated-ubiquitinated $\mathrm{I} \kappa \mathrm{B} \alpha s g \mathrm{~F}-\kappa \mathrm{B}$, and partial IKK complexes that contain ELKS, IKK $\beta s$ and/or IKK $\gamma g(\mathrm{NEMO})$. The association of HSP70 leads to stabilization of these intermediate complexes in a way that prevents proteasomal degradation of $I \kappa B \alpha$. Consequently, NF- $\kappa B$ is retained in the cytoplasm and is unable to induce inflammatory responses. 


\section{Conclusion}

HSPs are important mediators of a number of key intracellular reactions. Of importance to the care of the critically ill are their involvement in protein repair and tertiary structure. HSP70 is known to modulate inflammation and apoptosis. In models of acute lung injury and ARDS, over-expression of HSP70 improves outcome, ameliorates lung injury and attenuates inflammation. The involvement of HSP70 in other aspects of lung injury and in other components of MODS is under investigation.

Acknowledgement. Supported in part by NIH Grant GM 059930.

\section{References}

1. Davis TR (1974) Effects of heat on animals and man. Prog Biometeorol 1:228-238, 635-637

2. De Maio A (1999) Heat shock proteins: facts, thoughts and dreams. Shock 11:1-12

3. Snoeckx LH, Cornelussen RN, Van Nieuwenhoven FA, Reneman RS, Van Der Vusse GJ (2001) Heat shock proteins and cardiovascular pathophysiology. Physiol Rev 81:1461-1497

4. Feder ME, Hofmann GE (1999) Heat-shock proteins, molecular chaperones, and the stress response: evolutionary and ecological physiology. Annu Rev Physiol 61:243-282

5. Pilon M, Schekman R (1999) Protein translocation: how Hsp70 pulls it off. Cell 11:679-682

6. Kregel KC (2002) Heat shock proteins: modifying factors in physiological stress responses and acquired thermotolerance. J Appl Physiol 92:2177-2186

7. Frydman J (2001) Folding of newly translated proteins in vivo: the role of molecular chaperones. Annu Rev Biochem 70:603-647

8. Hartl FU, Hayer-Hartl M (2002) Molecular chaperones in the cytosol: from nascent chain to folded protein. Science 295:1852-1858

9. Yerbury JJ, Stewart EM, Wyatt AR, Wilson MR (2005) Quality control of protein folding in extracellular space. EMBO Rep 6:1131-1136

10. Rajan RS, Illing ME, Bence NF, Kopito RR (2001) Specificity in intracellular protein aggregation and inclusion body formation. Proc Natl Acad Sci USA 98:13060-13065

11. Hinault MP, Ben-Zvi A, Goloubinoff P (2006) Molecular chaperones: Cellular fold- controlling factors of toxic protein aggregates in neurodegenerative diseases. J Mol Neurosci (in press)

12. Hartl FU (1996) Molecular chaperones in cellular protein folding. Nature 381:571-579

13. Bukau B, Horwich AL (1998) The Hsp70 and Hsp60 chaperone machines. Cell 92:351-366

14. Whitesell L, Lindquist SL (2005) Hsp90 and the chaperoning of cancer. Nat Rev Cancer 5:761-772

15. Wegele H, Muller L, Buchner J (2004) Hsp70 and Hsp90-a relay team for protein folding. Rev Physiol Biochem Pharmacol 151:1-44

16. Westerheide SD, Morimoto RI (2005) Heat shock response modulators as therapeutic tools for diseases of protein conformation. J Biol Chem 280:33097-33100

17. Marber MS, Mestril R, Chi SH, Sayen MR, Yellon DM, Dillmann WH (1995) Overexpression of the rat inducible $70-\mathrm{kD}$ heat stress protein in a transgenic mouse increases the resistance of the heart to ischemic injury. J Clin Invest 95:1446-1456

18. Kluck CJ, Patzelt H, Genevaux P, et al (2002) Structure-function analysis of HscC, the Escherichia coli member of a novel subfamily of specialized Hsp70 chaperones. J Biol Chem 277:41060-4169 
19. Bellmann K, Wenz A, Radons J, Burkart V, Kleemann R, Kolb H (1995) Heat shock induces resistance in rat pancreatic islet cells against nitric oxide, oxygen radicals and streptozotocin toxicity in vitro. J Clin Invest 95:2840-2845

20. Klosterhalfen B, Hauptmann S, Tietze L, et al (1997) The influence of heat shock protein 70 induction on hemodynamic variables in a porcine model of recurrent endotoxemia. Shock 7:358-363

21. Tacchini L, Schiaffonati L, Pappalardo C, Gatti S, Bernelli-Zazzera A (1993) Expression of Hsp70, immediate-early response and heme oxygenase genes in ischemic-reperfused rat liver. Lab Invest 68:465-471

22. Wong HR, Wispe JR (1997) The stress response and the lung. Am J Physiol 273:L1-19

23. Schroeder S, Lindemann C, Hoeft A, et al (1999) Impaired inducibility of heat shock protein 70 in peripheral blood lymphocytes of patients with severe sepsis. Crit Care Med 27:1080-1084

24. Milberg JA, Davis DR, Steinberg KP, Hudson LD (1995) Improved survival of patients with acute respiratory distress syndrome (ARDS): 1983-1993. JAMA 273:306-309

25. Baue AE, Durham R, Faist E (1998) Systemic inflammatory response syndrome (SIRS), multiple organ dysfunction syndrome (MODS), multiple organ failure (MOF): are we winning the battle? Shock 10:79-89

26. Rubenfeld GD, Caldwell E, Peabody E, et al (2005) Incidence and outcomes of acute lung injury. N Engl J Med 353:1685-1693

27. Weiss YG, Bouwman A, Gehan B, Schears G, Raj N, Deutschman CS (2000) Cecal ligation and double puncture impairs heat shock protein 70 (Hsp70) expression in the lungs of rats. Shock 13:19-23

28. Smart SJ, Casale TB (1994) TNF-alpha-induced transendothelial neutrophil migration is IL-8 dependent. Am J Physiol 266:L238-L245

29. Vreugdenhil HA, Haitsma JJ, Jansen KJ, et al (2003) Ventilator-induced heat shock protein 70 and cytokine mRNA expression in a model of lipopolysaccharide-induced lung inflammation. Intensive Care Med 29:915-922

30. Durand P, Bachelet M, Brunet F, et al. (2000) Inducibility of the $70 \mathrm{kD}$ heat shock protein in peripheral blood monocytes is decreased in human acute respiratory distress syndrome and recovers over time. Am J Respir Crit Care Med, 161:286-292

31. Villar J, Ribeiro SP, Mullen JB, Kuliszewski M, Post M, Slutsky AS (1994) Induction of the heat shock response reduces mortality rate and organ damage in a sepsis-induced acute lung injury model. Crit Care Med 22:914-921

32. Weiss YG, Tazelaar J, Gehan BA, et al (2001) Adenoviral vector transfection into the pulmonary epithelium after cecal ligation and puncture in rats. Anesthesiology 95:974-982

33. Rosenfeld MA, Yoshimura K, Trapnell BC, et al (1992) In vivo transfer of the human cystic fibrosis transmembrane conductance regulator gene to the airway epithelium. Cell 68:143155

34. Dong JY, Wang D, Van Ginkel FW, Pascual DW, Frizzell RA (1996) Systematic analysis of repeated gene delivery into animal lungs with a recombinant adenovirus vector. Hum Gene Ther 7:319-331

35. Touqui L, Arbibe L (1999) A role for phospholipase A2 in ARDS pathogenesis. Mol Med Today 5:244-249

36. Weiss YG, Bellin L, Kim PK, et al (2001) Compensatory hepatic regeneration after mild, but not fulminant, intraperitoneal sepsis in rats. Am J Physiol Gastrointest Liver Physiol 280:G968-G973

37. Artigas A, Bernard GR, Carlet J, et al (1998) The American-European Consensus Conference on ARDS, part 2. Ventilatory, pharmacologic, supportive therapy, study design strategies and issues related to recovery and remodeling. Intensive Care Med 24:378-398

38. Weiss YG, Maloyan A, Tazelaar J, Raj N, Deutschman CS (2002) Adenoviral transfer of Hsp70 into pulmonary epithelium ameliorates experimental acute respiratory distress syndrome. J Clin Invest 110:801-806 
39. Andrejko KM, Chen J, Deutschman CS (1998) Intrahepatic STAT-3 activation and acute phase gene expression predict outcome after CLP sepsis in the rat. Am J Physiol 275:G1423-G1429

40. Deutschman CS, De Maio A, Buchman TG, Clemens MG (1993) Sepsis-induced alterations in phosphoenolpyruvate carboxykinase expression: the role of insulin and glucagon. Circ Shock 40:295-302

41. Deutschman CS, Andrejko KM, Haber BA, et al (1997) Sepsis-induced depression of rat glucose-6-phosphatase gene expression and activity. Am J Physiol 273:R1709-R1718

42. Schears GJ, Costarino AT (1999) Complexity of inflammatory mediators in acute respiratory distress syndrome (ARDS). J Pediatr 135:144-146

43. Malloy J, McCaig L, Veldhuizen R, et al (1997) Alterations of the endogenous surfactant system in septic adult rats. Am J Respir Crit Care Med 156:617-623

44. Ofenstein JP, Heidemann S, Juett A, Sarnaik A (1998) Endotoxin inhibits heat induced Hsp70 in rats. Crit Care Med 26 (Suppl 1):A 138 (abst)

45. Mosser DD, Caron AW, Bourget L, et al (2000) The chaperone function of hsp70 is required for protection against stress-induced apoptosis. Mol Cell Biol 20:7146-7159

46. Guzhova IV, Darieva ZA, Melo AR, Margulis BA (1997) Major stress protein Hsp70 interacts with NF-kB regulatory complex in human T-lymphoma cells. Cell Stress Chaperones 2:132139

47. Jaattela M, Wissing D, Bauer PA, Li GC (1992) Major heat shock protein hsp70 protects tumor cells from tumor necrosis factor cytotoxicity. EMBO J 11:3507-3512

48. Kitamura Y, Hashimoto S, Mizuta N, et al (2001) Fas/FasL-dependent apoptosis of alveolar cells after lipopolysaccharide-induced lung injury in mice. Am J Respir Crit Care Med 163:762-769

49. Serrao KL, Fortenberry JD, Owens ML, Harris FL, Brown LA (2001) Neutrophils induce apoptosis of lung epithelial cells via release of soluble Fas ligand. Am J Physiol Lung Cell Mol Physiol 280:L298-L305

50. Matute-Bello G, Liles WC, Steinberg KP, et al (1999) Soluble Fas ligand induces epithelial cell apoptosis in humans with acute lung injury (ARDS). J Immunol 163:2217-2225

51. Petrache I, Verin AD, Crow MT, Birukova A, Liu F, Garcia JG (2001) Differential effect of MLC kinase in TNF-alpha-induced endothelial cell apoptosis and barrier dysfunction. Am J Physiol Lung Cell Mol Physiol 280:L1168-L1178

52. Baud V, Karin M (2001) Signal transduction by tumor necrosis factor and its relatives. Trends Cell Biol 11:372-377

53. Akira S, Hoshino K, Kaisho T (2000) The role of Toll-like receptors and MyD88 in innate immune responses. J Endotoxin Res 6:383-387

54. Bromberg Z, Deutschman CS, Weiss YG (2005) Heat shock protein 70 and the acute respiratory distress syndrome. J Anesth 19:236-242

55. Beere HM, Wolf BB, Cain K, et al (2000) Heat-shock protein 70 inhibits apoptosis by preventing recruitment of procaspase-9 to the Apaf-1 apoptosome. Nat Cell Biol 2:469-475

56. Ravagnan L, Gurbuxani S, Susin SA, et al (2001) Heat-shock protein 70 antagonizes apoptosisinducing factor. Nat Cell Biol 3:839-843

57. Saleh A, Srinivasula SM, Balkir L, Robbins PD, Alnemri ES (2000) Negative regulation of the Apaf-1 apoptosome by Hsp70. Nat Cell Biol 2:476-483

58. Garrido C, Schmitt E, Cande C, Vahsen N, Parcellier A, Kroemer G (2003) HSP27 and HSP70: potentially oncogenic apoptosis inhibitors. Review Cell Cycle 2:579-584

59. Christman JW, Sadikot RT, Blackwell TS (2000) The role of nuclear factor-kB in pulmonary diseases. Chest 117:1482-1487

60. Hoffmann A, Levchenko A, Scott ML, Baltimore D (2002) The IkappaB-NF-kappaB signaling module: temporal control and selective gene activation. Science 298:1241-1245

61. Chen LW, Egan L, Li ZW, Greten FR, Kagnoff MF, Karin M (2003) The two faces of IKK and NF-kappa B inhibition: prevention of systemic inflammation but increased local injury following intestinal ischemia-reperfusion. Nat Med 9:575-581 
62. Ghosh S, May MJ, Kopp ER (1998) NF-kB and Rel proteins: Evolutionarily conserved mediators of immune responses. Annu Rev Immunol 16:225-260

63. Yamamoto Y, Kim DW, Kwak YT, Parjapati S, Verma U, Gaynor RB (2001) IKK /NEMO

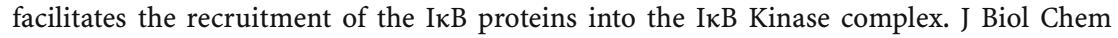
276:36327-36336

64. Mercurio F, Zhu H, Murray BW, et al (1997) IKK1 and IKK2: Cytokine-activated IkB kinases essential for NF- $\mathrm{KB}$ activation. Science 278:860-866

65. Poyet JL, Srinivasula SM, Lin JH, et al (2000) Activation of the I kappa B kinases by RIP via IKKgamma /NEMO-mediated oligomerization. J Biol Chem 275:37966-37977

66. Ducut Sigala JL, Bottero V, Young DB, Shevchenko A, Mercurio F, Verma IM (2004) Activation of transcription factor NF- $\kappa B$ requires ELKS, an IкB kinase regulatory subunit. Science 304:1963-1967

67. Read MA, Brownell JE, Gladysheva TB, et al (2000) Nedd8 modification of cul-1 activates SCF(beta(TrCP)-dependent ubiquitination of I kappaB alpha. Mol Cell Biol 20:2326-2333

68. Ben-Neriah Y (2002) Regulatory functions of ubiquitination in the immune system. Nat Immunol 3:20-26

69. Ciechanover A, Orian A, Schwartz A (2000) Ubiquitin-mediated proteolysis: biological regulation via destruction. BioEssays 22:442-451

70. Adams J (2003) The proteasome: structure, function, and role in the cell. Cancer Treat Rev 29 (suppl 1):3-9

71. Yoo CG, Lee S, Lee CT, Kim YW, Han SK, Shim YS (2000) Anti-inflammatory effect of heat shock protein induction is related to stabilization of I kappa B alpha through preventing I kappa B kinase activation in respiratory epithelial cells. J Immunol 164:5416-5123

72. Curry HA, Clemens RA, Shah S, et al (1999) Heat shock inhibits radiation-induced activation of NF-kappaB via inhibition of I-kappaB kinase. J Biol Chem 274:23061-23067

73. Malhotra V, Kooy NW, Denenberg AG, Dunsmore KE, Wong HR (2002) Ablation of the heat shock factor-1 increases susceptibility to hyperoxia-mediated cellular injury. Exp Lung Res 28:609-622

74. Ran R, Lu A, Zhang L, et al (2004) Hsp70 promotes TNF-mediated apoptosis by binding IKK gamma and impairing NF-kappa B survival signaling. Genes Dev 18:1466-1481

75. Weiss YG, Bromberg Z, Goloubinoff P, Deutschman CS (2005) HSP-70 Expression in the lung attenuates ARDS by disrupting NF- $\mathrm{kB}$. Intensive Care Med 31 (suppl 1):S45 (abst) 